\title{
PROFISSÁO E ESTRATIFICAÇÃO SOCIAL Desigualdades nas trajetórias de médicos e enfermeiros no Brasil atual
}

\section{Lucas Wan Der Maas}

E-mail: lucaswander@hotmail.com

\section{Alessandra Sampaio Chacham $(2)$}

E-mail: achacham@pucminas.br

\author{
Maria Carolina Tomás ${ }_{(2)}$ (D) \\ E-mail: mctomas@pucminas.br \\ (1) Núcleo de Educação em Saúde Coletiva da Universidade Federal de Minas Gerais (Nescon-UFMG), Belo Horizonte - MG, Brasil. \\ (2) Pontifícia Universidade Católica de Minas Gerais (PUC Minas), Belo Horizonte - MG, Brasil.
}

DOI: $10.1590 / 3610503 / 2020$

\section{Introdução}

O objetivo deste artigo é analisar as trajetórias profissionais de médicos e enfermeiros no Brasil atual, considerando tanto as diferenças entre as duas profissóes (inter) e dentro de cada uma delas (intra). Buscamos especificamente investigar os aspectos que são referidos pela literatura sociológica sobre profissóes como fatores de estratificação, hierarquização, diferenciação e ou desigualdade inter e intraprofissóes. Por isso, identificamos algumas trajetórias representativas de diferentes posiçóes profissionais no espaço profissional, delimitadas em torno de padrões de origem social, percurso escolar, inserção laboral e nichos técnicos de atuação na divisão do trabalho, além de marcadores sociais típicos de distinção social, como sexo, idade e classe social. A perspectiva aqui adotada é a da

Artigo recebido em: 07/05/2018

Aprovado em: 03/01/2020 multidimensionalidade das trajetórias, ao longo das quais os indivíduos são afetados por múltiplas posições sociais que ocupam em função de recursos que estão disponíveis na família de origem, no sistema escolar e no mercado de trabalho.

Partimos de uma abordagem quantitativa baseada na combinação de Análise de Correspondências Múltiplas (ACM) e Análise de Agrupamentos (cluster analysis) para identificação de trajetórias profissionais delineadas a partir da posição relativa dos agentes sociais no espaço profissional. Esse tipo de estudo se justifica pela possibilidade de realizar comparaçóes entre grupos profissionais, que são raros na sociologia das profissóes, buscando explicar as formas distintas e desiguais de obtenção de recompensas derivadas da inserção no mundo profissional. A escolha por essas duas profissóes se justifica por serem dois grupos opostos do ponto de vista da composição social e demográfica, do prestígio que comportam, da estrutura e dinâmica dos mercados de trabalho onde atuam e 
das formas de inserção laboral. Ao mesmo tempo, são grupos próximos na divisão do trabalho que se relacionam de forma direta e hierárquica.

$\mathrm{Na}$ área da saúde, tem-se uma divisão do trabalho caracterizada pela organização hierárquica em torno da prática médica hegemônica. Em geral, as ocupações, profissóes e funções não médicas ocupam posiçôes inferiores em diferentes escalas; mesmo que suas habilidades e saberes sejam aplicações do saber médico, suas funções e empregos são, normalmente, subordinados, e elas recebem menor prestígio do público leigo. Trata-se de um "sistema estratificado", que se conforma hierarquicamente de acordo com o prestígio e a autoridade vinculada a cada profissão, tendo a medicina como referência. Tal conformação reflete também a origem social dos profissionais, uma vez que os médicos derivam predominantemente de classes sociais de alta renda e os demais profissionais de posições inferiores. Além disso, nas profissóes não médicas há, frequentemente, sobrerrepresentação de mulheres, minorias étnicas e raciais e outros grupos socialmente desvalorizados, caso da enfermagem (Freidson, 2008).

Este estudo pretende se somar ainda ao diálogo sobre o contexto de expansão do ensino superior no Brasil nos anos 2000, em que se verificou maior diversificação da base social de recrutamento das profissóes e inflacionamento das credenciais de acesso ao mundo profissional. Aqui, mais uma vez, as possibilidades de comparação entre medicina e enfermagem se destacam. A medicina vivenciou esse processo de expansão do ensino superior a um ritmo de crescimento muito inferior à média das outras profissóes. A despeito da ampliação do recrutamento de pessoas derivadas de estratos de baixa renda nos cursos de medicina, os estratos de alta renda permaneceram majoritários. Não obstante, o mercado de trabalho médico apresentou sinais de dinamismo na geração de empregos e no incremento real dos rendimentos. Já a enfermagem vivenciou um cenário oposto com crescimento elevado de cursos e inversão de sua base social de recrutamento: de uma maioria de pessoas provenientes de estratos de renda média para estratos de baixa renda. $\mathrm{O}$ mercado de trabalho da profissão assistiu a altos níveis de desemprego e baixo retorno salarial, embora a criação de empregos tenha crescido consideravelmente (Girardi et al., 2014; Maas, 2018).

\section{Profissão como categoria de estratificação social}

Os diversos estudos sobre profissóes na sociologia, cada um à sua maneira, dedicaram-se a explorar os aspectos distintivos dos agrupamentos profissionais, seja pela atribuição de características que os diferenciam de outras ocupaçóes ou pela afirmação de sua importância como princípio de estruturação das sociedades modernas. Em geral, apesar do amplo espectro de possibilidades de interpretação sobre as profissóes nos sistemas de estratificação, disponível na literatura sociológica, um ponto recorrente é a ideia de que elas são formas distintas de posicionamento dos indivíduos na estrutura social. Isso ocorre pelo sucesso que esses grupos adquirem historicamente ao utilizar mecanismos de legitimação de diferenças e de exclusão, que conferem mais oportunidades de acesso às recompensas disponíveis no mercado de trabalho. Mais que isso, as profissóes são consideradas como grupos sociais sui generis, com identidade coletiva, estilos de vida e interesses próprios (Barbosa, 1993; Diniz, 1996; Weeden, 2002).

Essa visão sociológica sobre as profissóes permite tratá-las como uma categoria analítica essencial à compreensão das estruturas de desigualdade nas sociedades modernas, nas quais as credenciais fornecidas pelo sistema de ensino (principalmente superior), que habilitam os profissionais, ocupam um papel importante como variante dos processos de estratificação social (Diniz, 2001). Sob esse ponto de vista, a profissão é uma ocupação que se destaca na divisão do trabalho e na estrutura social porque mobiliza as credenciais disponíveis no sistema de ensino e recolhe recompensas derivadas da inserção em um mercado de trabalho hierarquizado segundo a importância conferida a essas credenciais. As profissōes, nesse sentido, são grupos cujos membros passam por treinamento prolongado em instituições profissionais responsáveis por controlar e distribuir credenciais e, que, portanto, se encontra fechada aos elegíveis, descrevendo chances semelhantes de obtenção de 
recompensas no mercado e de acesso a posiçôes sociais (Freidson, 1986).

O posicionamento social que ocorre a partir da profissão varia de acordo com o tipo e o nível de fechamento social (nos termos weberianos) historicamente produzido por cada grupo profissional. Tais variaçôes podem ser observadas de acordo com a composição demográfica e socioeconômica dos seus membros, os tipos de inserção no mercado de trabalho, a organização do sistema escolar e os valores socialmente atribuídos aos conteúdos do saber que cada profissão controla. Mesmo as diferenças de base técnica são socialmente atribuídas e descrevem uma forma de distinção social, que se traduz na posição de cada profissão no espaço social. As diferenças entre as profissóes e no interior de cada uma delas se baseiam também em fatores como a capacidade de exercício profissional no mercado privado, a contribuição oferecida aos interesses das organizaçóes empregadoras, o tipo de setor de atividade econômica predominante, o tipo de inserção laboral (empregado, autônomo, empregador etc.), o valor agregado ao tipo de saber controlado, da composição de gênero, entre outras (Brint, 1992; Barbosa, 1993; Weeden, 2002).

Seguindo a perspectiva bourdieusiana sobre os processos de estratificação no espaço social, as profissóes podem ser apreendidas como grupos que controlam de forma diferenciada o capital cultural, sendo possível considerá-las não só como conjuntos de pessoas com determinados padróes de acumulação de capitais (o que varia de um grupo para outro), mas também como produtoras de capital, na medida em que inculcam em seus membros identidades e estilos de vida próprios (Barbosa, 1993). É possível classificar as profissóes e analisar suas diferenças a partir dos valores de cada título, os quais demonstram capacidades distintas de produção de recompensas, que variam de acordo com a posição social historicamente conquistada por cada profissão. Este é um aspecto que evidencia o caráter de fechamento dos grupos profissionais e suas capacidades distintas de posicionamento na estrutura social.

O fechamento se efetiva não apenas em torno dos aspectos diretos da profissionalização (monopólio dos mercados, credencialismo, autoridade cultural etc.), mas também pela reprodução social realizada pelo recrutamento de membros que já conservam posiçóes destacadas no espaço social e que acumulam capitais herdados e adquiridos ao longo das trajetórias. Tendo em vista a origem social dos profissionais, a origem familiar é determinante dos percursos pessoais em direção ao posicionamento na estrutura social via profissionalismo. Nesse sentido, a credencial atua como um meio importante de mobilidade social ascendente, mas, sobretudo, de reprodução de estratos sociais de alta renda. Os diferenciais de seletividade de origem social no recrutamento das profissóes em termos de destino ocupacional e rendimentos destacam uma dinâmica própria do mundo profissional para produzir e reproduzir desigualdades (Bourdieu, 2007; Coradini, 2015).

Em suma, a análise das profissóes sob a perspectiva da estratificação social é importante, pois elas atuam como agentes de produção e reprodução de desigualdades. Isso ocorre porque existem distinçóes em termos de prestígio e vantagens econômicas e simbólicas que se processam em nível interprofissional, mas também entre indivíduos de uma mesma profissão que têm oportunidades diferentes adquiridas ao longo da vida (Brint, 1992; Diniz, 1996; Chaves e Morais, 2014). Em que pese o fato de ser um atributo adquirido, é nesse sentido que a profissão pode ser tratada como uma categoria de estratificação social da mesma forma que outros atributos clássicos como gênero, raça e classe social.

\section{Estratificaçáo profissional no contexto de expansáo do ensino superior}

Essa abordagem sobre as profissóes como categoria de estratificaçáo social se mostra relevante para a compreensão do contexto brasileiro recente, em que os mecanismos de entrada no mundo das profissóes foram alterados, seja pela expansão da base social de recrutamento do ensino superior ocorrida nos anos 2000, seja pela desvalorização das credenciais enquanto forma de obtenção de recompensas e posiçóes sociais que ocorre paralelamente. $\mathrm{Na}$ esteira desse contexto, a sociologia brasileira vem produzindo diversos estudos relativos ao mundo profissional, como resultado da necessidade de analisar as consequências do processo de expansão do ensino superior e as 
possíveis alterações na estrutura social, derivadas de maior acesso à escolaridade. Esses estudos podem ser divididos em dois grupos.

O primeiro é composto de trabalhos sobre estratificação educacional, que explicam a influência de marcadores sociais (gênero, raça, idade etc.) e das origens sociais no destino educacional dos indivíduos, tanto em termos de acesso ao ensino superior quanto da escolha das carreiras (Mont'Alvão, 2011, 2015; Barbosa e Santos, 2011; Prates e Collares, 2014; Barbosa, 2014; Artes e Ricoldi, 2015; Ribeiro e Schlegel, 2015; Brito, 2017). Uma primeira conclusão derivada desses estudos é que a base social de recrutamento das profissóes se alargou ao incluir paulatinamente grupos populacionais historicamente pouco representados, como mulheres, pardos, pretos e indivíduos de estratos sociais de baixa renda. Nesse sentido, ocorreu, de fato, diminuição dos efeitos de origem social para as chances de acesso e sucesso no ensino superior. Outra conclusão é a de que, apesar disso, ocorreu aumento da estratificação horizontal, isto é, da desigualdade no interior da população com nível superior de ensino. A tendência geral observada foi de mais desvantagens justamente para os grupos mais incluídos no processo: mulheres, pardos, pretos e aqueles já inseridos no mercado de trabalho, com origens sociais descapitalizadas, que escolheram profissóes consideradas menos prestigiadas e que estudaram em instituiçóes de ensino privadas.

De outro lado, localizam-se os estudos que analisaram a influência dos diplomas sobre os retornos individuais e acesso a posiçóes ocupacionais, bem como sobre a configuração da estrutura de classes sociais em um contexto de expansão da escolarização da população (Coradini, 2010, 2014, 2015; Guedes, 2010; Ribeiro, 2011, 2016; Reis e Machado, 2015; Santos, 2014, 2015; Madalozzo e Artes, 2015). De maneira geral, esses estudos mostraram que a estrutura social brasileira se modificou muito pouco e que, do ponto de vista do incremento educacional, ocorreu uma homogeneizaçáo da força de trabalho, resultando em redução das vantagens da população mais qualificada. Isso quer dizer que a maior escolarização foi importante para reduzir desigualdades, mas não para afetar os padróes gerais de acesso à estrutura social. Nesse quadro, o aumento absoluto de posições no mercado de trabalho equivalentes às profissões não foi suficiente, tendo em vista um cenário de mais competição por essas posiçóes, dado pelo expressivo aumento da oferta de credenciais. Assim como observado nos estudos sobre estratificação educacional, as desigualdades observadas no mercado de trabalho da população qualificada reservam desvantagens para mulheres, pardos, pretos, jovens e aqueles que escolheram as profissóes menos prestigiadas.

As evidências produzidas nesses estudos, portanto, levam ao questionamento do papel das credenciais como meio de superação das desigualdades sociais de origem, reforçando contrariamente a premissa do credencialismo de que mais educação produz mais igualdades de oportunidades e melhores empregos (Collins, 2013). Embora algumas evidências demonstrem casos efetivos de mobilidade social, sobretudo para os profissionais provenientes de estratos de baixa renda que passaram por escolas tradicionais, vivenciaram contextos mais integrados com a vida acadêmica ao longo da formação e escolheram profissões de prestígio (em especial medicina, direito e engenharia), o quadro geral foi de permanência e aprofundamento das desigualdades no mundo profissional (Barbosa, 2015).

É sintomático, por outro lado, que as variáveis mais utilizadas nesses estudos tenham sido as áreas de conhecimento, carreiras, cursos e ocupaçôes, e não as profissóes, mesmo que essas categorias estejam relacionadas. Acreditamos que deslocar o ponto de vista da análise partindo da perspectiva do mundo profissional permite olhar a profissão como uma instância que conecta os mundos da educação e do trabalho para produzir e reproduzir posiçôes sociais distintas. Mesmo em um cenário de inflacionamento e desvalorização do mundo profissional, não se pode reduzir o peso analítico de categorias sociais que conquistaram historicamente o domínio sobre seu espaço de ação na divisão do trabalho. As profissóes são categorias ocupacionais sui generis que descrevem trajetórias sociais de mobilização de recursos localizados precisamente nas credenciais fornecidas pelo sistema de ensino e nas recompensas derivadas da inserção em um mercado de trabalho hierarquizado segundo a importância conferida a essas credenciais (Larson, 2013). É nesse sentido que as profissóes devem ser entendidas como grupos que historicamente 
acumularam capacidades distintas de mobilizar recursos educacionais e organizacionais (de mercado), o que lhes confere pesos distintos para se colocar diante de cenários de inflacionamento de credenciais.

Como também destacou Bourdieu (2007), a intensificação da concorrência por diplomas em um contexto de alargamento das bases sociais no acesso ao ensino superior leva estratos das elites e classes médias a buscarem estratégias para reforçar a raridade de suas posiçôes derivadas da profissionalização. Assim, os capitais herdados pré-acesso ao mundo profissional se evidenciam enquanto recursos perante a desvalorização geral dos diplomas. Conforme os desprovidos de capitais herdados passam a ser afetados, mais do que o desencanto em relação à capacidade do título em prover retornos, tem-se uma intensificação da procura por educação. Os contextos sociais de desvalorização dos títulos, portanto, engendram o inflacionamento destes em função do aumento da concorrência por posiçóes no mercado. No espaço em que essas posiçôes são disputadas, os agentes estão desigualmente dispostos de acordo com o tipo de diploma e os capitais herdados. Não obstante, "a parcela dos que detêm recursos para resistir à desvalorização e, em particular o capital social associado a uma origem social elevada, cresce à medida que o indivíduo sobe na hierarquia dos diplomas" (Bourdieu, 2007, p. 126).

\section{Hipóteses de trabalho}

Com base na literatura apresentada e buscando atender ao objetivo do trabalho, elaboramos uma hipótese central como ponto de partida para a nossa investigação, da qual decorrem três questóes de pesquisa: as trajetórias profissionais tendem a se diferenciar entre as duas profissōes (inter) e dentro de cada uma delas (intra) de acordo com os recursos herdados da família de origem, o percurso de formação no ensino superior, o tipo de inserção profissional e os nichos técnicos de atuação na divisão do trabalho. As desigualdades decorrentes da origem familiar e da trajetória escolar produzem distinçôes nas trajetórias laborais e nas divisões técnicas de trabalho, reforçando o papel das profissóes como categorias de reprodução de desigualdades.
A partir dessa hipótese central, a primeira questão a ser analisada é a relação entre origem social e posições profissionais. Mais especificamente, busca-se analisar como as diferenças nas trajetórias de inserção laboral estão associadas à posição social da família de origem. Isso não significa negar ou diminuir a importância da formação profissional, mas reconhecer mais uma camada de determinação das trajetórias relativa aos recursos transmitidos pela família de origem, os quais são acumulados e mobilizados pelos agentes ao longo da vida (Bourdieu, 2007; Coradini, 2010; Chaves e Nunes, 2011; Chaves e Morais, 2014). Assim como já é conhecido para as duas profissões, esperamos identificar que a herança familiar está associada à profissão, uma vez que há maior presença de médicos provenientes das classes alta e média e de enfermeiros das classes média e baixa (Maas, 2018). De forma complementar, interessa identificar se as posiçóes no interior de cada profissão também se distribuem de forma distinta de acordo com a hierarquia das posiçóes sociais de origem.

Em segundo lugar, exploraremos as desigualdades nas trajetórias escolares, que refletem em grande medida as desigualdades advindas da família de origem. Mais especificamente, analisamos como a posição dos indivíduos profissionalizados está relacionada ao tipo de instituição de ensino frequentada e ao percurso escolar vivido. É certo que a hierarquia educacional tende a seguir a hierarquia social, uma vez que as Instituições de Ensino Superior (IES) operam não só por critérios técnicos, mas também segundo a origem social dos alunos. Contudo, interessam aqui os aspectos organizacionais da escola, enquanto ator que tem um papel específico de atenuar ou aprofundar as desigualdades, e a sua influência sobre o acesso a posiçóes no mercado profissional (Bourdieu, 2007; Dubet, Duru-Bellat e Vérétout, 2012; Coradini, 2015).

A terceira hipótese é sobre os nichos técnicos de divisão do trabalho no interior das profissóes. Segundo essa hipótese, os profissionais estariam segmentados em torno de funções e áreas de atuação, tendo em vista que as estratégias de fechamento, monopolização e valorização que ocorrem para o conjunto da profissão tendem a se repetir em seu interior, segundo a divisão do trabalho em torno funções, ações e tarefas. Nesse sentido, algumas 
distinções ocorrem pela delimitação de jurisdições em torno da base cognitiva da profissão, normalmente associadas ao exercício de funçōes especializadas, de direção, administração e docência. Tais funções refletem a obtenção de recompensas distintas, sejam elas financeiras ou de condiçôes de empregabilidade em setores específicos (Abbott, 1988; Brint, 1992; Grusky e Sorensen, 1998).

\section{Construção empírica das trajetórias}

As trajetórias das duas profissóes foram tratadas com base em uma visão bourdieusiana, como resultado de padróes sociais de biografias individuais, isto é, como percursos que os grupos sociais realizam no espaço social, experimentados por agentes ocupantes e postulantes de determinadas posiçóes ao longo do tempo. As trajetórias partem da visão geral sobre o espaço social, o qual é construído empiricamente como lócus de posiçóes e divisóes dos agentes sociais e de realização dos percursos individuais. As trajetórias são construídas sob um ponto de vista empírico segundo a análise da realização desses percursos, isto é, com o objetivo analítico de identificação de padrões sociais de divisão social e posicionamento na estrutura social (Montagner, 2007). Neste trabalho, as trajetórias foram construídas utilizando técnicas estatísticas, com o objetivo de organizar empiricamente o espaço profissional em torno de variáveis que descrevem os diferentes percursos individuais desde a família de origem, passando pela formação profissional, até a inserção laboral.

Devido à inexistência simultânea das variáveis de interesse em bases de dados secundários, optou-se por realizar coleta direta de dados junto a médicos e enfermeiros residentes no Brasil, através de um survey on-line. Os profissionais foram convidados a participar por intermédio de redes de contato pessoal e profissional e de compartilhamento do link da pesquisa em redes sociais, perfazendo uma amostra não probabilística, constituída principalmente por indicação. Os casos levantados náo têm representatividade estatística das populaçóes em questão, mas refletem uma diversidade de trajetórias profissionais nelas existentes. A chamada foi destinada a pessoas com diploma em medicina ou enfermagem, independentemente de estarem trabalhando ou não na profissão.

O questionário era autoaplicável por um formulário estruturado, criado na plataforma Google Forms, contendo perguntas sobre aspectos sociodemográficos, origem social, formação, inserção no mercado de trabalho e percepção sobre pertencimento de classe e mobilidade social. Foi elaborado um questionário para cada profissão com as mesmas questôes; em algumas delas, variaram as possibilidades de resposta segundo o caso. Na elaboração das perguntas, utilizou-se como referência o questionário socioeconômico do Exame Nacional de Desempenho de Estudantes (Enade) para orientar a maior parte dos quesitos sobre origem social e formação na graduação. Os quesitos sobre nichos técnicos de atuação foram construídos a partir da análise da legislação profissional pertinente a cada caso (BRASIL, 1986; BRASIL, 2013; CFM, 2016).

Foi realizado um piloto para correção de possíveis inconsistências. O formulário permaneceu ativo entre 28 de setembro e 18 de dezembro de 2017. Estima-se que o preenchimento tomou 10 minutos, em média, levando em consideração que o respondente pôde se recusar a responder parte ou a totalidade das perguntas, sem prejuízo à sua participação. Para este artigo, utilizaram-se os dados de 374 respondentes, sendo 188 médicos e 186 enfermeiros. ${ }^{1}$ Embora não houvesse restrição de participação, só responderam pessoas que estavam ocupadas como médicos ou enfermeiros (considerando o trabalho em assistência direta à saúde, de direção na área da saúde ou de pesquisa e docência em medicina, enfermagem e saúde pública), isto é, não houve respostas de pessoas ocupadas fora da profissão.

Para a identificação das trajetórias, inicialmente construímos o espaço profissional das duas profissóes utilizando a Análise de Correspondências Múltiplas (ACM). A escolha dessa técnica se justifica, inicialmente, pela natureza não aleatória da amostra do survey, o que exigiu um procedimento não inferencial de análise multivariada para verificar a relação entre inúmeras variáveis categóricas. Ao mesmo tempo, a técnica tem se mostrado bastante relevante aos estudos de estratificação, por permitir a representação do espaço social sob a perspectiva relacional da posição social dos indivíduos, como é o caso dos trabalhos 
de Bertoncelo (2016, 2019) e Coradini (2015). No Brasil, alguns trabalhos recentes lançaram mão de ACM para análise de categorias ocupacionais como diplomatas, economistas, engenheiros e ocupantes de cargos públicos diversos, como sugere o levantamento feito por Klüger (2018).

A ACM é uma técnica de estatística exploratória multidimensional, cujo objetivo é verificar a associação entre variáveis categóricas em uma tabela de contingência complexa, em que os indivíduos estão dispostos na linha e as categorias das variáveis na coluna. Na prática, representa, em um espaço geométrico, a relação entre as linhas e colunas, o que é feito pela redução da dimensionalidade da representação dos dados. A tabela é "substituída" por um gráfico de baixa dimensão, no qual os indivíduos e modalidades (categorias) aparecem dispostos com distâncias relativas, de tal forma que as distribuiçôes semelhantes na tabela de contingência geram pontos próximos e as distribuiçóes díspares geram pontos distantes entre si (Mingoti, 2005).

Como o objetivo principal era identificar desigualdades inter e intraprofissóes que se processam ao longo das trajetórias individuais, construímos uma ACM em que todos os quesitos de origem familiar, percurso escolar, inserção profissional e nichos técnicos de atuação na divisão do trabalho foram inseridos como variáveis ativas. Os atributos demográficos de sexo, idade e cor/raça e o indicativo da profissão foram inseridos como variáveis suplementares. Nota-se que as variáveis suplementares entram no modelo com "massa zero", não interferindo na constituição das distâncias entre os agentes e as modalidades, porém, são úteis como forma de análise complementar (Klüger, 2018). Também foram incluídas como suplementares variáveis sobre percepção de classe social e de mobilidade social e sobre posse de bens (automóvel, imóvel, ativos financeiros e empresa). Essas variáveis suplementares não foram inseridas como ativas por não se constituírem como atributos representativos das trajetórias individuais, embora possam refletir tanto aspectos da herança familiar quanto de retornos derivados da inserção no mundo profissional. Sua consideração permite ampliar o entendimento sobre o posicionamento dos agentes no espaço social, dada pela percepção dos mesmos e, de forma mais objetiva, pela posse de recursos econômicos. Em resumo, o modelo é constituído de 16 variáveis e 54 modalidades ativas, assim como descritas no Quadro 1, e 10 variáveis suplementares.

Para a identificação efetiva das trajetórias, realizamos uma Análise de Agrupamentos a partir dos resultados da ACM. Essa estratégia permitiu identificar agregados de indivíduos que compartilham posiçóes semelhantes no espaço profissional em torno das trajetórias que se iniciam na família de origem, perpassam o percurso escolar e culminam na inserção no mercado de trabalho. Esse tipo de exercício é comum na solução de diversos problemas em ciências sociais, sendo utilizado para identificar padróes de subgrupos amostrais, de forma que cada um deles contenha atributos semelhantes em seu interior e distintos em relação aos casos dos demais subgrupos (Mingoti, 2005). Resumidamente, a ACM identifica a associação entre as variáveis e a análise de cluster identifica os subgrupos, utilizando os resultados gerados anteriormente. $\mathrm{Na}$ área da sociologia das profissóes, utilizamos como referência para a aplicação combinada das duas técnicas o trabalho de Chaves e Nunes (2011), que identificou segmentos de inserção profissional entre advogados de Lisboa.

\section{Perfil da amostra}

Uma breve descrição da amostra (Tabela 1) destaca que a maioria dos respondentes é do sexo feminino, o que era de se esperar, pela predominância de mulheres na enfermagem. Mesmo na medicina, a proporção de mulheres se mostrou elevada diante do que se esperaria para esse grupo, caso a amostra fosse representativa da população total. Isso se explica quando observamos a distribuição etária dos respondentes, que tende a se concentrar nas faixas etárias até os 39 anos, onde as mulheres já são maioria. Quanto à cor ou raça, as duas profissōes apresentaram distribuiçóes semelhantes: a maioria brancos, seguida de expressiva representação de pardos e poucos casos de pretos e amarelos e um único indígena. A distribuição da amostra segundo regiâo geográfica de moradia apresenta uma composição semelhante nas duas profissões, o que também não é muito distinta do esperado, isto é, concentração na regiấo Sudeste, presença significativa no Nordeste e 


\section{Quadro 1}

Descrição das variáveis e modalidades ativas incluídas na ACM

\begin{tabular}{|c|c|c|}
\hline $\begin{array}{l}\text { ORIGEM SOCIAL } \\
\text { Ocupaçáo do agregado familiar } \\
\text { Empresários e dirigentes (Empres/Dirg) } \\
\text { Profissionais de alto nível (Prof alto) } \\
\text { - médico/a, dentista, arquiteto/a, } \\
\text { engenheiro/a, advogado/a, juiz/a, } \\
\text { economista, psicólogo/a etc. } \\
\text { Profissionais de baixo nível (Prof } \\
\text { baixo) - enfermeiro/a, farmacêutico/a, } \\
\text { nutricionista, fisioterapeuta, } \\
\text { professor/a, pedagogo/a, contador/a, } \\
\text { assistente social etc. } \\
\text { Não Manual de Rotina (NMR) } \\
\text { - técnicos/as de nível médio e } \\
\text { trabalhadores do apoio administrativo } \\
\text { ou do comércio } \\
\text { Comerciante/Autônomo (Comelauto) } \\
\text { Manual/Rural (Manual/Rural) - } \\
\text { operários da indústria, trabalhadores } \\
\text { dos serviços, trabalhadores rurais }\end{array}$ & $\begin{array}{l}\text { Número de atividades na graduaçáo } \\
\text { (estágio, extensáo, pesquisa etc.) } \\
\text { Nenhuma (NenhumaAtiv) } \\
\text { Uma (UmaAtiv) } \\
\text { Duas (DuasAtiv) } \\
\text { Três ou mais (TresAtiv ou +) } \\
\text { Pós-graduaçáo concluída } \\
\text { Especializaçáo lato sensu/Residência } \\
\text { (Lato sensu/Resid) } \\
\text { Mestrado/Doutorado (Stricto sensu) } \\
\text { Ambas - lato e stricto (AmbasPós) } \\
\text { Nenhuma (NenhumaPós) } \\
\text { INSERÇÁO PROFISSIONAL } \\
\text { Tipo de inserçáo no setor público } \\
\text { Funcionário público (FuncPúblico) } \\
\text { Temporário (Temporário) } \\
\text { Terceirizado (Terceirizado) } \\
\text { Múltiplos arranjos (MultArranjPub) } \\
\text { Nenhuma (NenhumPub) } \\
\text { Tipo de inserçáo no setor privado } \\
\text { Empregado com carteira de trabalho } \\
\text { (Empr s/ carteira) } \\
\text { Empregado sem carteira de trabalho } \\
\text { (Empr c/ carteira) } \\
\text { Autônomo/Cooperado (Auton/Cooper) } \\
\text { Múltiplos arranjos (MultArranjPub) } \\
\text { Nenhuma (NenhumPri) } \\
\text { Número de trabalhos } \\
\text { Um (UmTrab) } \\
\text { Dois (DoisTrab) } \\
\text { Três ou mais (TrêsTrab ou +) }\end{array}$ & $\begin{array}{l}\text { Carga horária semanal } \\
\text { Até } 39 \text { horas (Até } 39 h) \\
\text { De } 40 \text { a } 44 \text { horas }(40-44 h) \\
\text { De } 45 \text { a } 60 \text { horas }(45-60 h) \\
\text { Mais de } 60 \text { horas }(+60 h) \\
\text { Rendimento em todos os trabalhos } \\
\text { Até } \mathrm{R} \$ 2.811,00 \\
\text { De R } \$ 2.812,00 \text { a R } \$ 4.685,00 \\
\text { De R } \$ 4.686,00 \text { a } \$ 9.370,00 \\
\text { De R } \$ 9.371,00 \text { a } \mathrm{R} \$ 18.740,00 \\
\text { Mais de R } \$ 18.740,00 \\
\text { NICHOS TÉCNICOS DE } \\
\text { ATUAÇÃO } \\
\text { Realiza funçóes de chefia, direçáo e } \\
\text { coordenaçáo de serviços de saúde } \\
\text { Sim (Chefia/Dir) } \\
\text { Não (N) } \\
\text { Realiza funçóes de ensino e pesquisa } \\
\text { em saúde pública } \\
\text { Sim (Ensino/SPub) } \\
\text { Não (N) } \\
\text { Realiza funçóes de clínica básica/saúde } \\
\text { da família } \\
\text { Sim (ClinBásica) } \\
\text { Não (N) } \\
\text { Realiza procedimentos especializados } \\
\text { Sim (Especializ) } \\
\text { Não (N) }\end{array}$ \\
\hline
\end{tabular}

Fonte: pesquisa "Desigualdades no mundo profissional: trajetórias de médicos e enfermeiros no Brasil entre 1991 e 2010".

Sul e baixa no Centro-Oeste e Norte. Os estados com maior número de respondentes foram Minas Gerais, São Paulo e Rio Grande do Sul, Ceará, Pernambuco, Bahia, Maranhão e Paraná.

A maioria dos profissionais ingressou nos cursos de medicina e enfermagem nos anos 2000. Destes, contudo, observou-se a concentração das entradas em períodos distintos para cada profissão, já que os enfermeiros ingressaram em maior volume de 2002 a 2009 e os médicos de 2006 a 2009. Por isso, a maioria dos enfermeiros concluiu o curso na mesma década, predominantemente entre 2006-2010, e a maioria dos 
Tabela 1

Perfil da amostra por profissáo

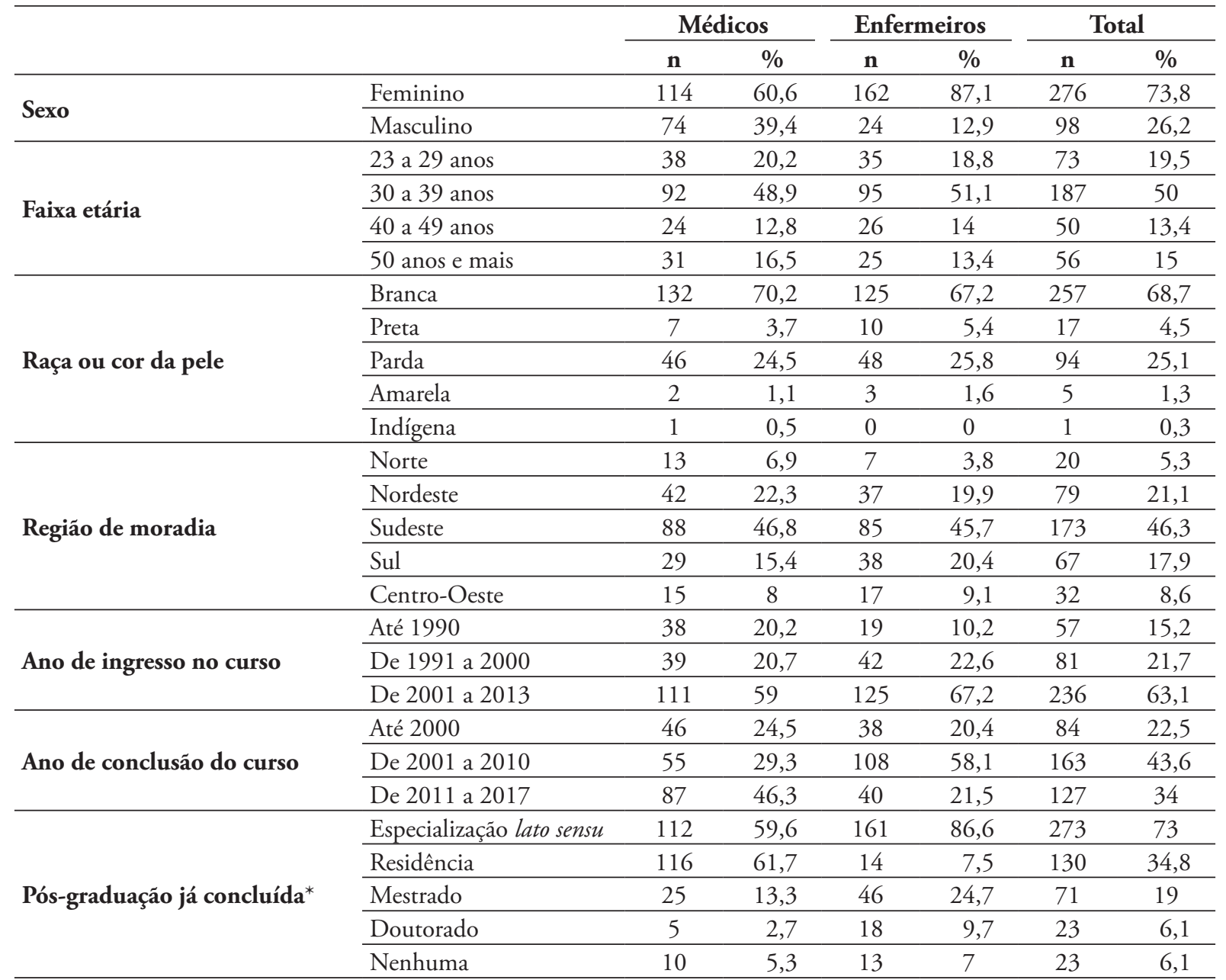

Fonte: pesquisa "Desigualdades no mundo profissional: trajetórias de médicos e enfermeiros no Brasil entre 1991 e 2010".

*Aceita múltipla resposta. Obs.: Os percentuais foram calculados a partir do total de casos válidos em cada variável.

Os números de participantes que não responderam foram omitidos da tabela.

médicos no quadriênio seguinte, entre 2011 e 2014. Mais de $90 \%$ dos participantes fizeram algum tipo de pós-graduação, sendo a especialização lato sensu a mais comum (incluindo residência médica). Os respondentes com mestrado e doutorado são mais frequentes entre enfermeiros. Trata-se, portanto, de uma amostra altamente qualificada, o que deve influenciar nos tipos de trajetórias que serão analisadas posteriormente.

Uma comparação possível com as tendências observadas nas últimas décadas permite localizar a amostra do survey em relação à população total das duas profissões. ${ }^{2}$ Ao longo do processo de expansão do ensino superior no Brasil, iniciado no segundo quinquênio dos anos 1990 e continuado nos anos 2000 e início dos anos 2010, houve ampliação da base de recrutamento das duas profissóes. Nesse sentido, aumentou a participação relativa de mulheres na medicina e de homens na enfermagem. As duas profissóes passaram por rejuvenescimento, embora medicina tenha se mantido ainda bastante envelhecida, em função de um tempo médio maior de retirada do mercado de trabalho, relativamente aos enfermeiros, os quais seguem um padrão típico da força de trabalho 
assalariada. A participação de pretos e pardos também aumentou, sobretudo destes últimos (Girardi et al., 2014). De maneira geral, a amostra se alinha ao resultado desses movimentos de recomposição demográfica, entretanto se apresenta ainda mais jovem e mais feminina do que se esperaria para a população total em 2017. É composta principalmente por jovens que ingressaram na graduação no período correspondente à expansão do ensino superior, especialmente nos anos 2000. Em relação à raça, é possível que a amostra tenha uma composição muito próxima da população total, no caso da medicina, mas um pouco diferente em relação à enfermagem, quando era de se esperar maior número de pardos e pretos.

\section{Análise das trajetórias ${ }^{3}$}

A ACM foi realizada para os 374 casos selecionados da amostra, isto é, os 188 médicos e 186 enfermeiros ocupados na profissão com respostas completas em todas as variáveis ativas. Os resultados geram a nuvem de modalidades e a nuvem de indivíduos (ou agentes) que podem ser interpretadas como mapas relacionais (Bertoncelo, 2019) ou como a representação do espaço social (Bourdieu, 2007; Klüger, 2018). O número de eixos que cortam as nuvens de modalidades e de agentes é de 38 (dado por $\mathrm{K}-\mathrm{Q}$, em que $\mathrm{K}$ é o número de modalidades ativas e $\mathrm{Q}$ é o número de variáveis ativas). Cada eixo explica uma porção variável da variância total da nuvem (sendo esta dada por K/Q - 1). Para a análise, foram retidos os três primeiros eixos, cuja proporção somada de contribuição para a variância total da nuvem é de $46 \%$. Embora outros eixos pudessem ser retidos, ampliando a proporção total de explicação, utilizamos como critério aqueles com autovalor (Eigenvalue) acima da média da variância do eixo (dada por 100/54 = 1,852) (ver Gráfico 1).

O Gráfico 1 apresenta o espaço profissional considerando a representação da nuvem de modalidades ativas dos dois primeiros eixos retidos. O primeiro

\section{Gráfico 1}

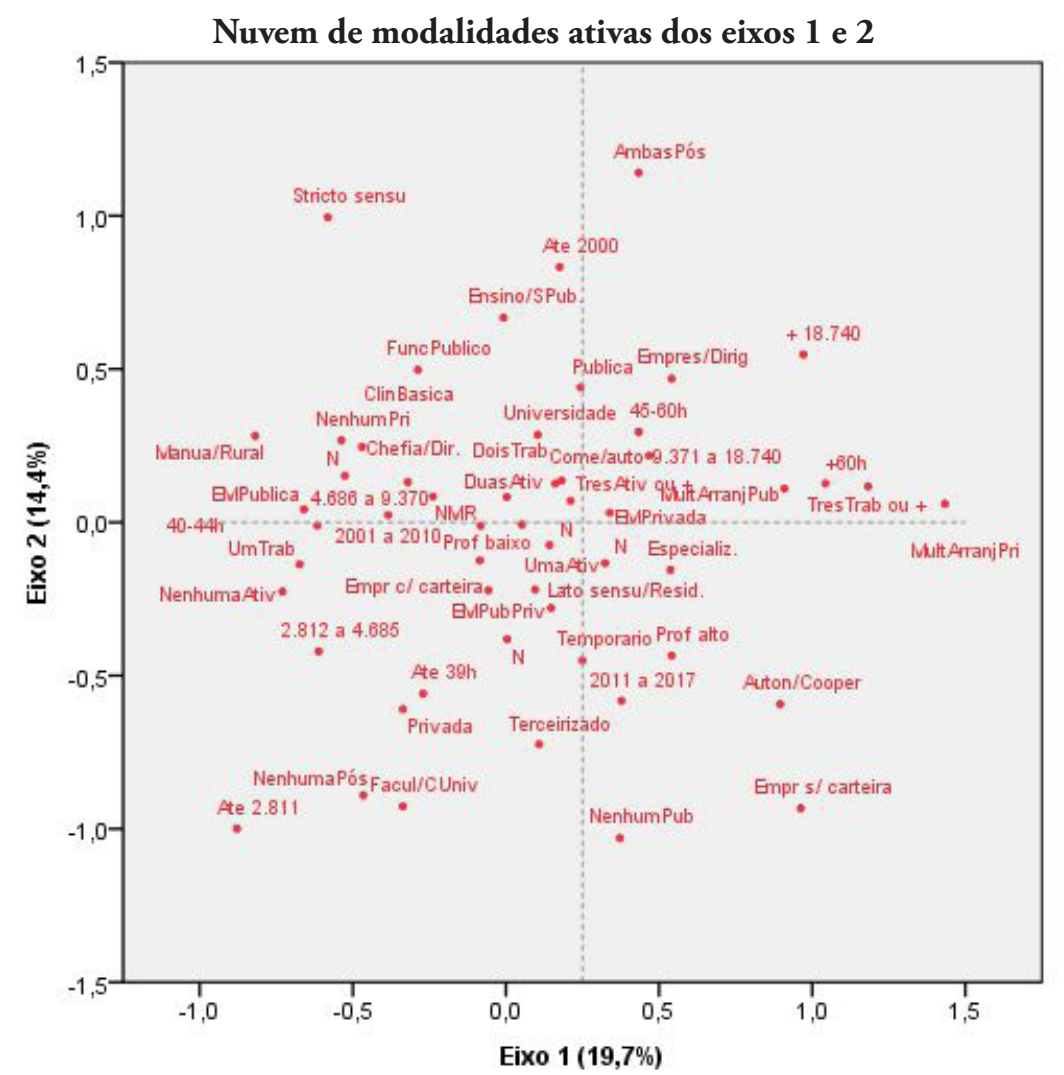

Fonte: pesquisa "Desigualdades no mundo profissional: trajetórias de médicos e enfermeiros no Brasil entre 1991 e 2010". 
eixo contribui em 19,7\% para a variância total da nuvem. Estrutura-se em oposiçóes em torno das modalidades de inserção profissional, em especial as relativas às variáveis de número de trabalhos, carga horária semanal e rendimento. À direita se concentram características típicas de uma inserção profissional liberal com múltiplos vínculos (três ou mais trabalhos) nos setores privado e público, perfazendo quantidades elevadas de carga horária semanal (mais de 60 horas) e rendimentos, e com práticas especializadas, de maior complexidade técnica. Enquanto à esquerda, temos uma inserção assalariada típica em um único trabalho de tempo integral (40 a 44 horas) e remuneração intermediária. Há proximidade com a vinculação de funcionário público e nenhum vínculo com o setor privado, ainda que o tipo empregado com carteira de trabalho também esteja presente nessa região. Em oposição aos procedimentos especializados, aparecem nessa região as modalidades relativas a funções de clínica básica/saúde da família e de direção, chefia e coordenação de serviços de saúde.

A oposição que se estrutura através do eixo 1 também é demarcada em função dos atributos de herança familiar. A primeira variável é a ocupação do agregado familiar, correspondente à ocupação mais elevada, do pai e ou da mãe, no momento em que o respondente frequentava o ensino médio. ${ }^{4}$ As modalidades que indicam pais em ocupaçóes de empresários e dirigentes, profissionais de alto nível e comerciantes e autônomos, estão mais próximas das modalidades que caracterizam a inserção liberal dos respondentes. Já as ocupações de profissionais de baixo nível, não manual de rotina (NMR) e manual/rural estão mais próximas das modalidades de inserção assalariada típica. Alinhando-se com as associaçóes verificadas anteriormente, as modalidades de tipo de escola em que frequentou o ensino médio indicam uma aproximação entre ensino médio em escola privada (integral ou parcialmente) com a inserção liberal, à direita do eixo 1, e de ensino médio integral em escola pública com a inserção assalariada, à esquerda.

O interessante a se observar aqui é como cada conjunto de modalidades de inserção profissional se atrela a determinado tipo de herança familiar e em que medida isso contribui para compreender a estratificação no espaço profissional, que se processa conforme oportunidades distintas que os profissionais tiveram ao longo da vida. Há uma associação entre inserção liberal típica em múltiplos arranjos com pais em grupos ocupacionais da classe média. No caso de pais empresários/as ou dirigentes, demonstra-se a importância da transmissão de recursos econômicos e de estilos de vida relacionados ao empreendedorismo para ocupar a posiçấo mais capitalizada dentro do espaço profissional. No caso de pais profissionais de alto nível, tem-se uma fonte destacada para circulação e acumulação de recursos sociais e culturais, podendo também incluir os econômicos. A inserção assalariada com predominância no setor público está mais próxima de pais em posiçóes mais baixas dentro da classe média, no caso de profissionais de baixo nível, ou fora dela, ${ }^{5}$ no caso dos estratos NMR e manual/rural. Trata-se de uma correspondência a um estilo de vida distanciado do empreendedorismo e mais próximo a valores racional-burocráticos.

O eixo 2 contribui em $14,4 \%$ para a variância total da nuvem. Nele, as oposiçóes se operam principalmente em torno das modalidades indicativas do percurso escolar (graduação e pós-graduação) dos respondentes. No que se refere à graduação, observa-se na parte superior e mais ao centro da nuvem as características de formação em instituições de ensino públicas e do tipo universidade. Na região inferior à esquerda, aparecem instituiçóes privadas e do tipo faculdade/centro universitário. Ressalta-se que essas características se aproximam da modalidade de nenhuma atividade durante a graduação (indica que o respondente não realizou atividades de pesquisa, extensão e estágio). $\mathrm{O}$ ano de formação também estabelece uma hierarquia evidente: na parte inferior se encontra a modalidade de conclusão do curso entre 2011 e 2017, ao centro, o período entre 2001 a 2010, e na parte superior, até 2000. Também seguindo a mesma hierarquia, está a pós-graduação, com a modalidade de nenhuma pós-graduação na parte inferior, especialização lato sensu ou residência ao centro e stricto sensu (mestrado e doutorado) e ambas na parte superior. Outra característica que contribui para a explicação desse eixo é realização de funçóes de ensino e pesquisa em saúde pública, que se coloca na parte superior do espaço profissional, provavelmente associada à qualificação do tipo stricto sensu. 
Nesse ponto, é interessante ressaltar que os resultados corroboram as características observadas no processo de expansão do ensino superior dos anos 2000. De maneira geral, parece haver uma hierarquia que se processa mediante a diferenciação institucional das IES, aspecto que se relaciona à questáo do percurso do ensino superior, conforme hipótese estabelecida. De um lado, localizam-se as universidades públicas, consideradas de maior prestígio e que, em geral, oferecem uma vivência mais integrada ao ambiente acadêmico, com atividades de pesquisa, extensão e estágio. De outro lado, estáo as IES privadas, de menor prestígio, que se desenvolveram nos últimos anos, predominantemente faculdades e centros universitários, as quais foram as que mais cresceram impulsionadas por políticas de expansão e democratização do acesso (Prates e Collares, 2014).
O Gráfico 2 apresenta a nuvem de modalidades suplementares. Seguindo as oposiçóes estruturadas pelo eixo 1, a principal distinção é, de fato, interprofissional, na medida em que a medicina e enfermagem se encontram em lados opostos da nuvem. De fato, a inserção laboral observada em cada uma das regiōes opostas se aproxima do padrão esperado para cada grupo, isto é, uma inserção mais tipicamente liberal entre médicos e mais assalariada entre enfermeiros. $\mathrm{Na}$ mesma linha, a variável sexo também segue essa oposição quando se vê o sexo masculino mais próximo da medicina e o sexo feminino da enfermagem. Quanto à raça/cor da pele, porém, ocorre uma associação inesperada, já que o agregado preta/parda/indígena está mais próximo da região direita e o agregado branca/amarela da região esquerda. Essa associação, porém, pode estar relacionada ao perfil dos respondentes.

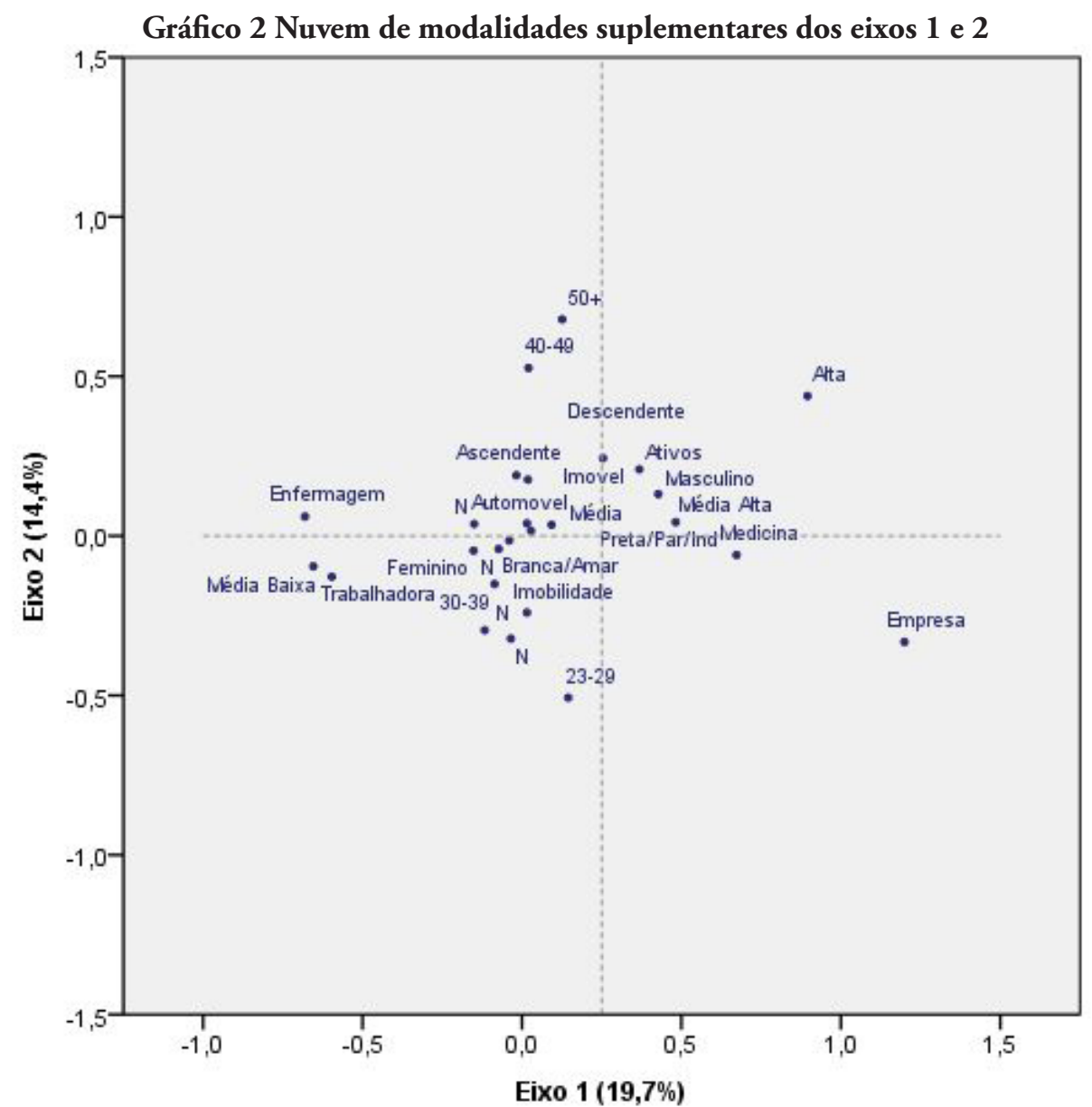

Fonte: pesquisa “Desigualdades no mundo profissional: trajetórias de médicos e enfermeiros no Brasil entre 1991 e 2010 ”. 
Como destacamos anteriormente, a proporção de pessoas que se declararam pretos e pardos está sub-representada na amostra de enfermeiros, o que pode ter afetado esse resultado. A idade do respondente segue a hierarquia observada no eixo 2 quanto ao ano de formação na graduação. Nesse sentido, a idade aumenta de baixo para cima.

As modalidades referentes à percepçáo sobre classe e mobilidade social após a profissionalização, e de posse de bens (automóvel, imóvel, ativos financeiros e empresa) tendem a seguir a estrutura observada no eixo 1 para os atributos de origem social que, por sua vez, também se associa com o tipo de inserção laboral. Os profissionais se percebem predominantemente como parte da classe média, mas as distinçóes inter e intraprofissóes relativizam o significado dessa posição. ${ }^{6} \mathrm{~A}$ percepção de pertencimento à classe média baixa e classe trabalhadora está mais próxima das modalidades de inserção assalariada e dos agregados familiares NMR e manual/rural. Por outro lado, o pertencimento à classe média alta e alta está mais próximo das modalidades de inserção liberal e agregados familiares de empresários e dirigentes e profissionais de alto nível. Os resultados evidenciam que os agentes se percebem no espaço profissional seguindo uma hierarquia compatível com sua posição.

O centro do gráfico concentra a situação mais típica da amostra em termos de percepção sobre mobilidade social, que é a modalidade ascendente. A imobilidade está deslocada para baixo em relação ao eixo 2, destacando uma percepçáo relacionada aos profissionais mais jovens e que se formaram entre 2011 e 2017. Aqui temos tanto indivíduos provenientes de classes baixas que ainda não reconhecem a titulaçấo como fonte de ascensão social, o que faz sentido no estágio inicial da carreira, quanto os provenientes das classes média e alta que de fato mantiveram a posição social herdada dos pais. Por fim, as modalidades de posse de automóvel, de imóvel e de ativos financeiros estão no meio da nuvem, mas é interessante notar que os ativos se aproximam da classe média alta. A posse de empresa é o que mais claramente se distancia do centro, posicionando-se na regiâo referente à inserção profissional liberal.

A comparaçáo objetiva entre a percepçáo e os padróes encontrados na análise da herança familiar corrobora a hipótese central de que a profissionalização é tanto uma estratégia de ascensão social em direção à classe média quanto de reproduçấo desta. Os movimentos de ascensão social se destacam mais entre enfermeiros e profissionais com inserção assalariada, que são aqueles com origem mais demarcada nos estratos NMR e manual/rural (à esquerda do eixo 1). Já a reprodução se destaca mais entre médicos e profissionais com inserção liberal, provenientes dos estratos de empresários e dirigentes e profissionais de alto nível (à direita do eixo 1). Nesse sentido, os diferenciais de seletividade de origem social no recrutamento das profissóes em termos de destino ocupacional e rendimentos destacam uma dinâmica própria do mundo profissional para produzir desigualdades.

O Gráfico 3 apresenta a nuvem de modalidades ativas que mais contribuem para o eixo 3 (11,9\% para a variância total da nuvem). Esse eixo organiza o espaço profissional pelos atributos de tipo de inserção nos setores público e privado, número de trabalhos, carga horária, ocupação do agregado familiar e tipo de pós-graduação concluída. É muito parecido com o eixo 1; no entanto, verificam-se associaçôes específicas. De forma mais evidente, na região inferior à esquerda, temos uma associação entre emprego com carteira no setor privado e nenhuma vinculação com o setor público. Seguindo a estruturação do eixo 2, sabe-se que essa é uma regiâo mais provável para respondentes em início de carreira que auferem baixos rendimentos. Na região mais ao centro e à direita, se observa uma associação entre ocupação dos pais como empresários e dirigentes, formação stricto sensu, realização de três ou mais atividades na graduação (estágio, extensão etc.), existência de dois trabalhos e carga horária de 45 a 60 horas. Remete a um tipo de inserção de profissionais provenientes da classe média alta, que tiveram um percurso de formação para atuação na área acadêmica; desse modo, os três fatores apontados pela hipótese central: (1) herança familiar, (2) percurso do ensino superior e (3) inserção profissional se mostram interdependentes. Ressalta-se que esse tipo de inserção não se restringe ao ambiente universitário, pois pode haver acúmulo com um segundo trabalho em serviços assistenciais, por exemplo. Uma terceira associaçáo que se pode destacar é a vinculação como autônomo, cooperado 


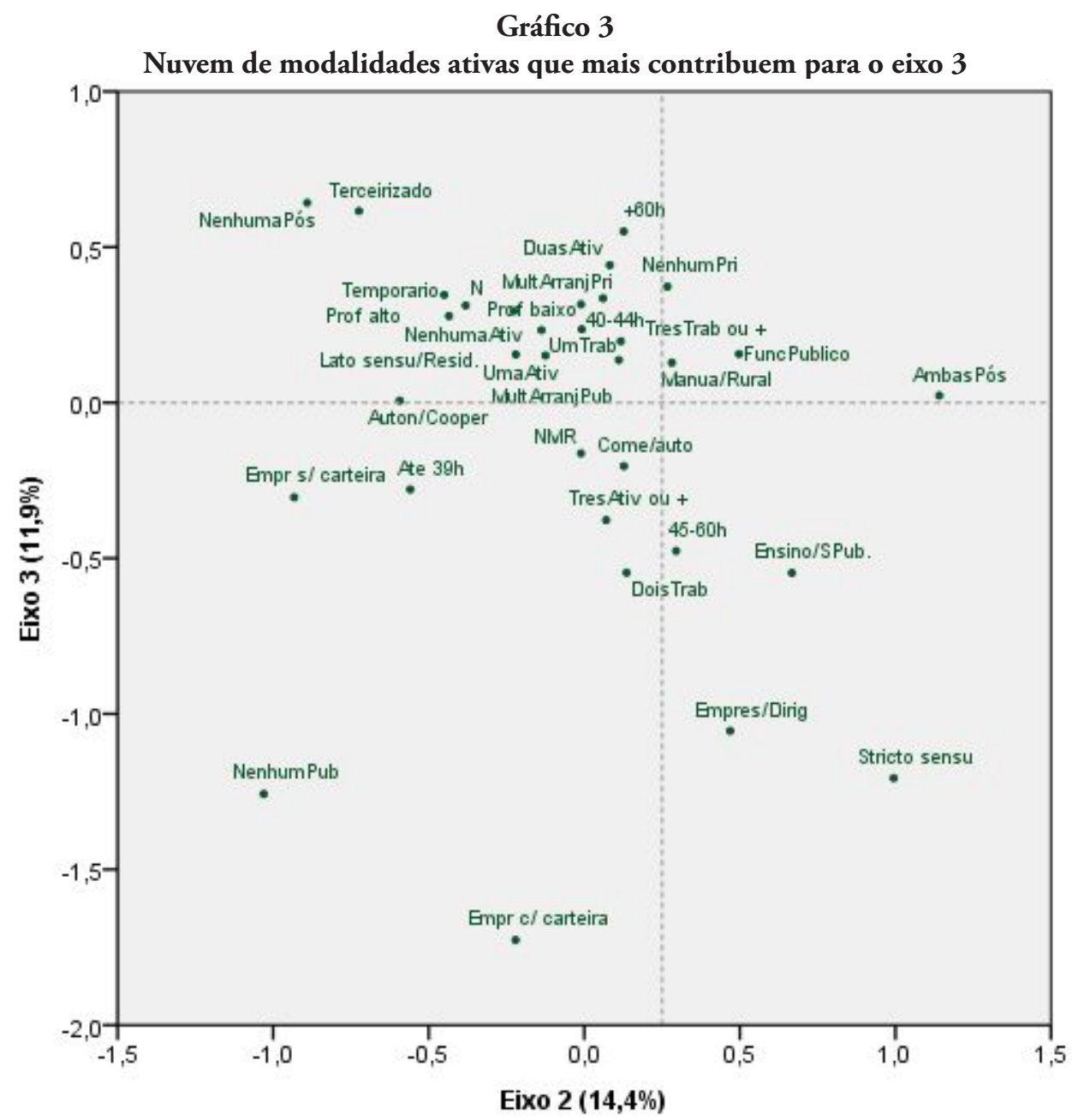

Fonte: pesquisa "Desigualdades no mundo profissional: trajetórias de médicos e enfermeiros no Brasil entre 1991 e 2010".

ou empregado sem carteira no setor privado e carga horária de até 39 horas, o que provavelmente é o tipo de inserção mais precário da amostra.

Até aqui, os resultados da ACM permitiram caracterizar o espaço profissional por meio do exame das associaçóes entre as modalidades e a distribuiçáo dos agentes. Para delimitar mais claramente as trajetórias profissionais, foi realizada uma análise de cluster, utilizando as coordenadas dos agentes (object scores) em todos os eixos da ACM como variáveis de input. $\mathrm{O}$ resultado permitiu delinear agrupamentos de profissionais com trajetórias semelhantes, isto é, com combinações em torno dos atributos de herança familiar, percurso de formação e inserção no mercado de trabalho. A definição quanto ao número de agrupamentos partiu da verificaçáo dos possíveis pontos de corte em um dendograma que apontou cortes em 5, 6 e 7 agrupamentos. Todas as opçôes foram avaliadas quanto à composiçáo dos agrupamentos, de modo que optamos pelo corte em 5 devido à caracterização mais arredondada que foi observada, já que 6 ou 7 grupos gerariam trajetórias muito semelhantes. ${ }^{7}$ A Tabela 2 apresenta a frequência de casos em cada agrupamento, por profissão. O Gráfico 4 apresenta a nuvem de agentes segundo o pertencimento a cada um dos clusters, construída a partir das coordenadas dos respondentes nos eixos 1 e 2 da ACM.

O cluster 1 é composto por 54 enfermeiros e 3 médicos e se localiza mais à esquerda do eixo $1 \mathrm{e}$ 
Tabela 2

Distribuição da amostra por cluster e profissáo

\begin{tabular}{lccccccccc}
\hline & \multicolumn{3}{c}{ Medicina } & \multicolumn{3}{c}{ Enfermagem } & \multicolumn{3}{c}{ Total } \\
\cline { 2 - 10 } & $\mathbf{n}$ & $\begin{array}{c}\text { \% na } \\
\text { profissáo }\end{array}$ & $\begin{array}{c}\text { \% no } \\
\text { cluster }\end{array}$ & $\mathbf{n}$ & $\begin{array}{c}\text { \% na } \\
\text { profissáo }\end{array}$ & $\begin{array}{c}\text { \% no } \\
\text { cluster }\end{array}$ & n & $\begin{array}{c}\text { \% na } \\
\text { amostra }\end{array}$ & $\begin{array}{c}\text { \% no } \\
\text { cluster }\end{array}$ \\
\hline Cluster 1 & 3 & 1,6 & 5,3 & 54 & 29,0 & 94,7 & 57 & 15,2 & 100,0 \\
\hline Cluster 2 & 21 & 11,2 & 21,6 & 76 & 40,9 & 78,4 & 97 & 25,9 & 100,0 \\
\hline Cluster 3 & 67 & 35,6 & 83,8 & 13 & 7,0 & 16,3 & 80 & 21,4 & 100,0 \\
\hline Cluster 3 & 59 & 31,4 & 92,2 & 5 & 2,7 & 7,8 & 64 & 17,1 & 100,0 \\
\hline Cluster 5 & 38 & 20,2 & 50,0 & 38 & 20,4 & 50,0 & 76 & 20,3 & 100,0 \\
\hline Total & $\mathbf{1 8 8}$ & $\mathbf{1 0 0 , 0}$ & $\mathbf{5 0 , 3}$ & $\mathbf{1 8 6}$ & $\mathbf{1 0 0 , 0}$ & $\mathbf{4 9 , 7}$ & $\mathbf{3 7 4}$ & $\mathbf{1 0 0 , 0}$ & $\mathbf{1 0 0 , 0}$ \\
\hline
\end{tabular}

Fonte: pesquisa "Desigualdades no mundo profissional: trajetórias de médicos e enfermeiros no Brasil entre 1991 e 2010 ”.

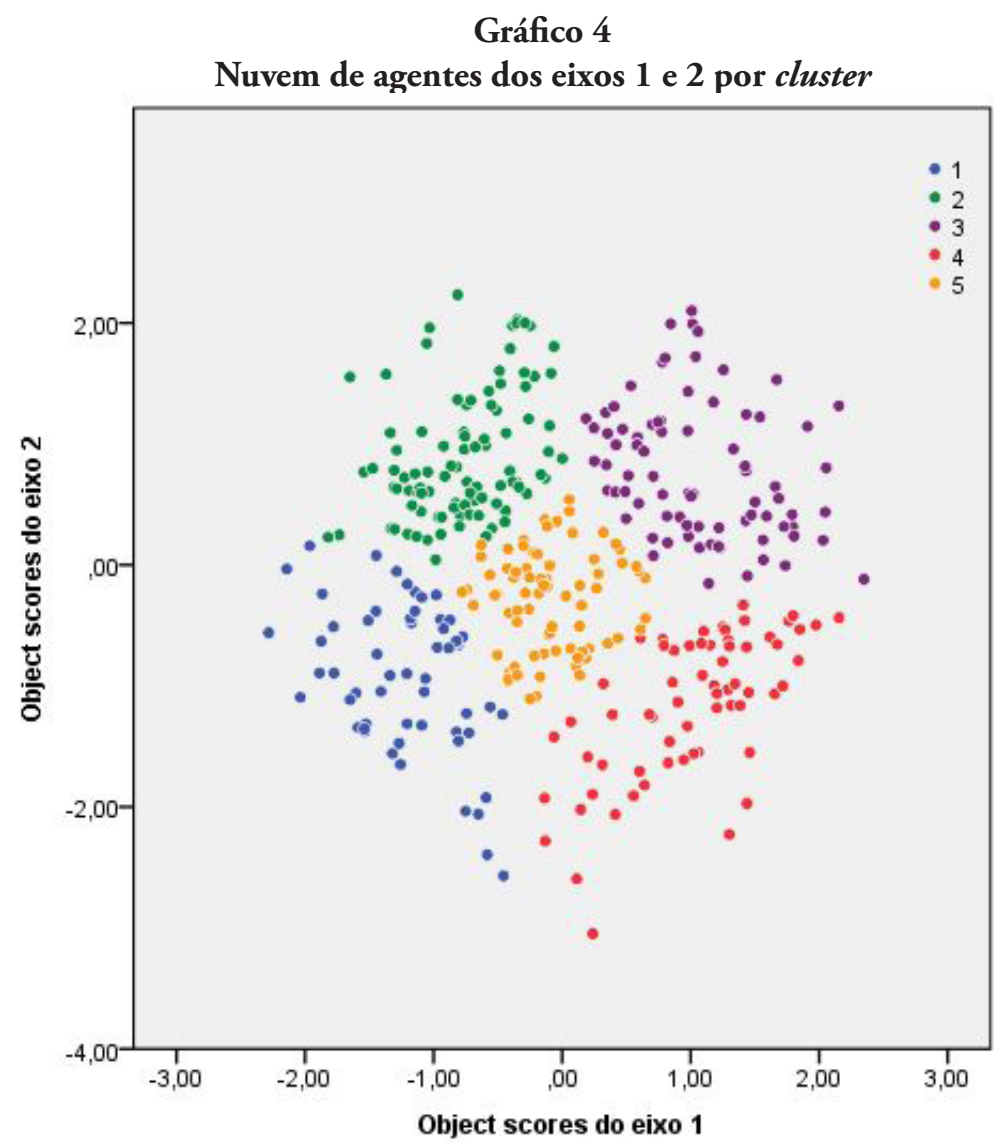

Fonte: pesquisa "Desigualdades no mundo profissional: trajetórias de médicos e enfermeiros no Brasil entre 1991 e 2010".

mais abaixo do eixo 2 da nuvem de agentes. Descreve trajetórias predominantemente de profissionais do sexo feminino com pais em ocupaçóes NMR e Manual/Rural, embora haja presença significativa de pais profissionais. A maioria estudou em escolas públicas no ensino médio e em instituições privadas na graduação, sobretudo faculdades e centros universitários. Em geral, estão em um único trabalho do tipo assalariado, com predominância do setor público e baixa empregabilidade no setor privado, carga horária integral e os salários mais baixos da amostra. A maioria realiza atividades de clínica básica/saúde da família. É um tipo de inserção profissional menos capitalizada; entretanto, se considera um ganho de 
mobilidade social a posição de assalariamento no setor público em regime integral, tendo em vista a realidade do mercado de trabalho brasileiro. Não é desprezível o fato de que esses profissionais entraram para o sistema de ensino superior como resultado da expansão deste e vivenciaram um processo de ascensão social perante a ocupação do agregado familiar. Porém, ainda que inseridos no espaço profissional, ocupam uma posição inferior na comparação tanto inter quanto intraprofissional.

O cluster 2 é composto por 76 enfermeiros e 21 médicos. Na nuvem de agentes, se localiza à esquerda do eixo 1 e acima do eixo 2 . O perfil aqui é muito parecido com o anterior em termos de composiçáo por sexo e origem social, mas a participação masculina é maior e mais significativa ainda a presença de respondentes com pais em ocupaçóes do estrato manual/rural. Também é maior a presença de pessoas que frequentaram o ensino médio em escola privada. A principal distinção desse grupo é a predominância de formação em universidades públicas e existência de pós-graduação stricto sensu. A inserção no mercado de trabalho ocorre no setor público para quase todos os casos, o que explica o fato de a maioria realizar funções de ensino e pesquisa em saúde pública e ou de clínica básica/saúde da família. A formação posterior à graduação define essa trajetória, diferenciando um segmento de profissionais altamente qualificados, o que tem um papel central para sua diferenciação no mercado, dada por maiores remuneraçóes e a possibilidade de acumular trabalhos. Entre os enfermeiros, reflete a posição mais capitalizada dentro da profissão, sendo uma trajetória mais duradoura para acumular credenciais como forma de distinção. Já entre os médicos, reflete uma posição intermediária, cujos retornos de rendimento são menores do que a inserção liberal e maiores do que a inserção de empregados sem carteira de trabalho.

O cluster 3 é formado por 67 médicos e 13 enfermeiros. As trajetórias se iniciam principalmente em famílias com pais em ocupaçôes de classe média, com destaque para empresários, dirigentes, comerciantes, autônomos e profissionais de alto nível. A maioria frequentou escolas particulares no ensino médio e universidades públicas na graduação, além de a maioria ter concluído o curso até 2010, com importante participação dos egressos anteriores à década de 2000. A maioria fez especialização, também sendo expressiva a formação stricto sensu. A inserção profissional ocorre predominantemente de forma liberal em três ou mais empregos, em múltiplos arranjos, tanto no setor público quanto no privado, com elevada carga horária e rendimentos. Mais capitalizada, essa inserção profissional se dá pelo acúmulo de trabalhos em múltiplos mercados, isto é, pela combinação entre emprego no setor público, trabalho autônomo no mercado privado e, em alguns casos, propriedade ou sociedade de consultórios e clínicas.

O cluster 4 é formado por 59 médicos e 5 enfermeiros. Está representado na nuvem de agentes à direita do eixo 1 e abaixo do eixo 2. Trata-se de um grupo semelhante ao anterior em termos de origem social, mas aqui há maior participação do estrato de profissionais de alto nível e menor presença de empresários e dirigentes. Também se evidencia a diferença em termos de formação na graduação, já que a maioria se formou entre 2011 e 2017 e estudou em instituições privadas. A inserção profissional ocorre em múltiplos trabalhos, mas de forma menos qualificada, com valores mais baixos de participação no setor público, carga horária semanal, rendimento e número de trabalhos. Mesmo entre aqueles que estão no setor público, a principal forma de vinculação é via terceirização. No mercado privado, predominam as relaçóes autônomas/cooperadas, sendo também comum o emprego sem carteira de trabalho. Os médicos com os menores retornos no mercado também se ocupam de forma autônoma, sem vínculo empregatício. Descrevem uma trajetória que ainda está em início da carreira, o que explicaria a desvantagem por si só, não fosse o fato de estarem mais atrelados a percursos em faculdades privadas e terem se formado em um contexto de desvalorização da renda entre os mais jovens, comparativamente aos pares em estágio avançado na carreira.

O cluster 5 localiza-se ao centro da nuvem de distribuição, sendo igualmente composto pelas duas profissões, com 38 profissionais em cada caso. Devido a essa posição, caracteriza-se em torno dos atributos mais frequentes da amostra. A maioria é de mulheres, com pais profissionais (de alto e baixo nível) ou em ocupaçóes NMR e que estudaram o ensino 
médio em escola privada. Predominam os casos de graduação a partir do ano 2000 em universidades públicas ou privadas, com continuidade da formaçâo em pós-graduação lato sensu. Em termos de inserção profissional, concentram-se no setor público e têm expressiva presença no mercado privado, perfazendo rendimentos próximos da média amostral, auferidos em um ou dois trabalhos com dedicação em tempo integral. Os principais nichos técnicos de atuação encontram-se em serviços assistenciais, tanto exercendo funçóes de clínica básica/saúde da família, quanto procedimentos especializados, mas também há expressivo volume em funçôes de saúde pública.

\section{Discussáo e conclusão}

As trajetórias identificadas (apesar de não serem as únicas possíveis) constataram a importância da herança familiar e dos percursos no ensino superior (graduação e pós) para o acesso a posiçóes destacadas nos mercados profissionais, demonstrando a inter-relação dessas características expostas em nossa hipótese central. Adicionalmente, se identificou que o período de formaçáo e a idade dos profissionais refletem ainda momentos distintos de exposição ao ensino superior e de estágio na carreira, importantes também para a diferenciação inter e intraprofissōes. Além disso, encontramos clara segmentação de gênero, já que as trajetórias menos capitalizadas tendem à maior participação feminina, em comparação à masculina. Nesse sentido, as diferenças inter e intraprofissooes tanto reproduzem quanto reforçam as desigualdades no interior do espaço profissional. Tais diferenças se expressam igualmente na forma de percepção dos respondentes. Embora se percebam predominantemente como parte da classe média, os médicos manifestam menor pertencimento à classe média baixa e estáo distantes de se perceberem como parte da classe trabalhadora, e os enfermeiros se localizam em menor frequência como parte das classes média alta e alta.

Como forma de resumir os resultados encontrados, o Gráfico 5 apresenta novamente a nuvem de agentes dos eixos 1 e 2, agora identificando a profissão de cada caso. Nota-se uma regiáo mais à direita povoada predominantemente por médicos e mais à esquerda por enfermeiros, o que demarca clara hierarquia em torno das oposiçōes: inserção liberal versus assalariada e origem na classe média versus fora da classe média. Em termos de recompensas e condiçóes de trabalho, os médicos mais à direita estão na posição mais capitalizada, enquanto os enfermeiros mais à esquerda na posiçáo menos capitalizada. Nesse sentido, as principais características que demarcam as desigualdades interprofissōes são o rendimento $\mathrm{e}$ a capacidade de se inserir no mercado de trabalho, combinando vínculos autônomos no setor privado, emprego público e posse de empresa. Esse destino profissional está mais associado à origem social de classe média, com destaque para os estratos de dirigentes, empresários, comerciantes e profissionais de alto nível.

A região de maior combinação entre as duas profissóes é o centro da nuvem, convergindo características que são mais típicas na amostra. Outra regiáo de contato é a que se localiza mais à esquerda do eixo $1 \mathrm{e}$ mais acima do eixo 2 , onde se apresenta com maior frequência um tipo de inserção profissional típica do funcionalismo público dedicado a funçóes de ensino e pesquisa em saúde pública e com existência de pós-graduação stricto sensu. A hierarquia que se processa em torno do eixo 2 impacta nas desigualdades observadas no interior de cada profissão, tendendo as trajetórias a se diferenciarem de cima para baixo em funçáo da oposição entre formação em universidades públicas versus faculdades e centros universitários privados. Não obstante, essas características também estão associadas à herança familiar medida pela ocupação do agregado familiar. Como se assistiu no período de expansão do ensino superior nos anos 2000 , a maior penetração dos estratos de baixa renda nos cursos de graduação ocorreu em instituições privadas.

Entre os médicos, os profissionais em posiçôes mais qualificadas tendem a se ocupar em múltiplos trabalhos e funçôes especializadas, sendo fundamental o acúmulo de ocupaçôes como empreendedor, assalariado no setor público e autônomo no mercado privado. Esses profissionais estão associados a percursos que se iniciam em uma família formada por pais também empreendedores e/ou profissionais de alto nível, passando por escolas privadas no ensino médio, graduação em universidades públicas, alta integração à vida acadêmica e pós-graduação lato sensu e stricto 


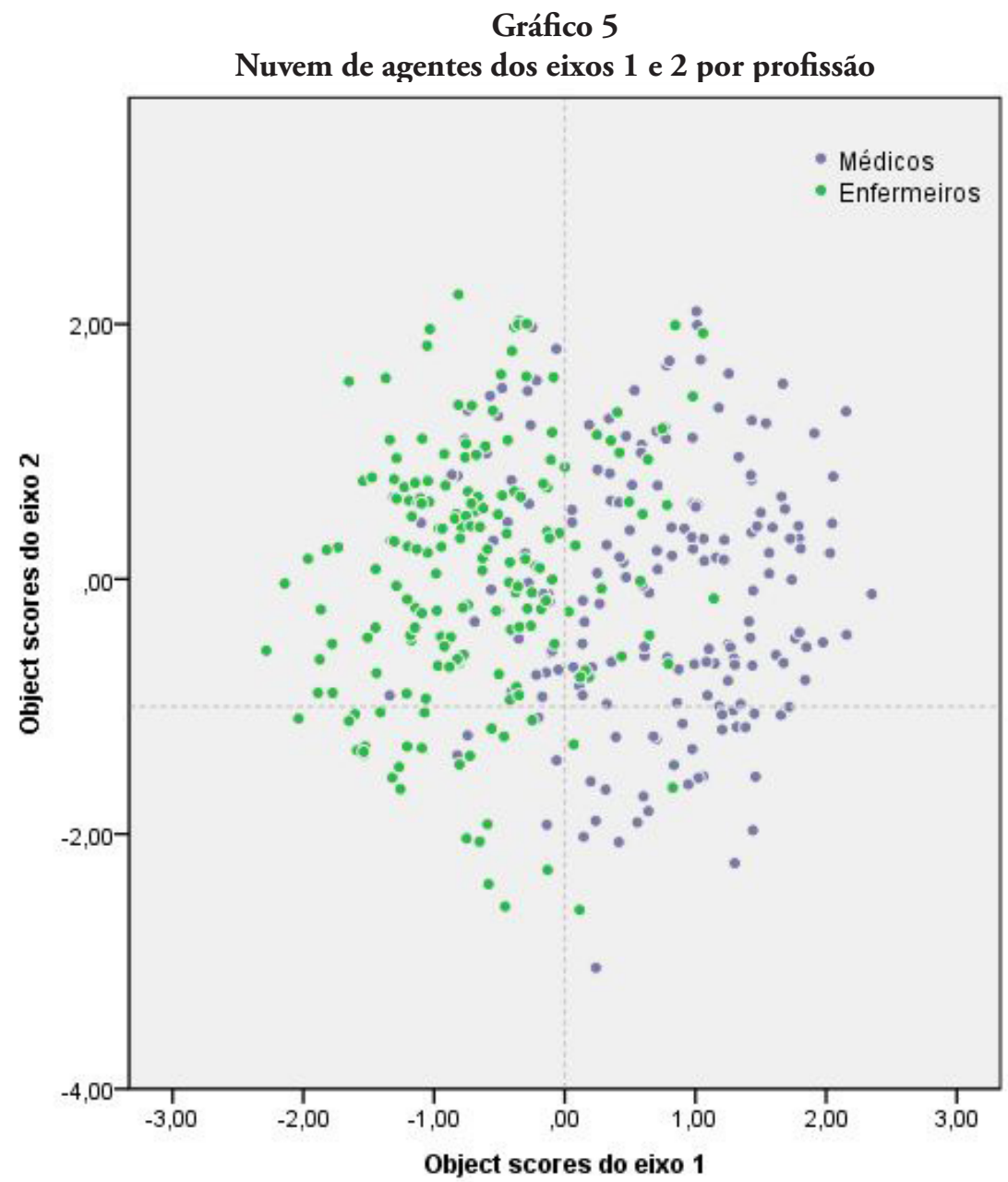

Fonte: pesquisa "Desigualdades no mundo profissional: trajetórias de médicos e enfermeiros no Brasil entre 1991 e 2010".

sensu. Já os médicos assalariados em tempo integral no setor público, derivam em maior grau de famílias com pais profissionais de baixo nível ou NMR, estando mais associados a um modelo burocrático de profissionalização, exercendo funções de clínica básica/saúde da família e saúde pública. Os médicos com menores retornos no mercado também se ocupam de forma autônoma, sem vínculo empregatício. Descrevem uma trajetória que ainda está no início da carreira, podendo representar um contexto de mercado de trabalho mais retraído em termos de geração de empregos públicos.

Entre os enfermeiros, há maior homogeneidade no que se refere às relações de trabalho, tendo em vista a predominância do assalariamento. As trajetórias apontam predominantemente para percursos de ascensão social, tendo em vista a predominância de indivíduos da amostra cujos pais não ocupavam posiçôes de classe média. De qualquer maneira, observa-se uma hierarquia nas recompensas derivadas da inserção profissional. As posições assalariadas típicas no funcionalismo público são em geral ocupadas por profissionais provenientes de famílias com pais em ocupações de rotina e manuais. A melhor posição entre os enfermeiros está associada ao uso de credenciais elevadas (mestrado e doutorado) e ao exercício profissional conjugado entre docência no ensino superior e atividades de cuidado. Existe ainda uma hierarquia que se evidencia pelo montante de remuneração equivalente à quantidade de horas trabalhadas, de forma que a vinculação em regime integral no setor público e a multiplicidade de trabalhos tende a favorecer a posição individual com base nesses atributos. 
Tais trajetórias, se analisadas como parte do processo de expansão do ensino superior e do mundo profissional como um todo, ocorrido no Brasil nos anos 2000, reforçam o entendimento em torno do papel das profissóes como mecanismo de estratificação. Um dos objetivos deste trabalho foi compreender o significado desse momento, afinal as profissōes se destacam como fonte diferenciada de inserção na economia capitalista, na medida em que atendem necessidades que exigem pessoal qualificado para atuar nos governos e organizaçóes modernas. Mas as profissōes fazem parte de um contexto social amplo, sendo apenas um dos aspectos que afetam a estruturação da sociedade. A profissionalizaçáo, enquanto um processo de diferenciação social, isto é, de realização ou manutenção de posiçóes sociais derivadas da posse de uma credencial de nível superior opera por meio de desigualdades estruturantes da sociedade brasileira e por dinâmicas próprias do mundo profissional. As profissóes atuaram nesse contexto como fontes destacadas de permanência e aprofundamento de desigualdades sociais. A despeito da ampliação e democratização do mundo profissional, ainda há sérios desafios a serem enfrentados na direção de uma sociedade efetivamente inclusiva e democrática.

\section{Agradecimentos}

Agradecemos à Capes pelo financiamento da pesquisa aprovada pelo CEP-PUC Minas, aos participantes do estudo, aos que divulgaram seu questionário e aos pareceristas da RBCS.

\section{Notas}

1 A pesquisa coletou, ao todo, 436 respostas. Os casos não utilizados neste artigo são de médicos e enfermeiros desocupados ou não economicamente ativos. Entre os ocupados, o número total foi de 388, mas 14 casos foram desconsiderados por falta de resposta em modalidades ativas da ACM.

2 Dados gerais sobre as duas profissóes poderiam ser coletados no Censo Demográfico e na Pesquisa Nacional por Amostra de Domicílios (PNAD) do IBGE, porém, entendemos que esse levantamento fugiria do escopo do presente trabalho. Além do mais, nenhuma das duas fontes permite agregar informaçóes sobre herança familiar, percurso escolar na graduação, inserção no mercado de trabalho e nichos técnicos de atuação.

3 Optamos por priorizar a análise por meio dos gráficos de nuvens de modalidades e agentes, omitindo as tabelas de resumo do modelo (com os resultados dos autovalores e das proporçóes da variância explicada) e de contribuiçáo das modalidades da ACM e o dendograma da análise de cluster.

4 A escolaridade do pai e da mãe não foi incluída (ainda que tenha sido perguntada), tendo em vista que a ocupação representa mais diretamente o tipo de herança que pode ser transmitida, não obstante a forte relaçáo entre escolaridade e ocupação.

5 Concordamos com Ribeiro (2011) ao indicar como parte da classe média os agregados ocupacionais de empresários e dirigentes e de profissionais de nível superior, tanto de alto quanto de baixo nível. Nesse caso, não se incluem como parte da classe média as ocupaçóes denominadas de não manuais de rotina.

6 Em função da hipótese de que os profissionais tendem a se localizar na classe média, optou-se por uma classificação que permitisse verificar diferentes níveis de pertencimento, por isso as categorias da variável classe social derivam do trabalho de Salata (2014), que é a seguinte: classe alta, média alta, média, média baixa, trabalhadora e baixa/pobre. Tal decisão se mostrou acertada, tendo em vista que a maioria dos respondentes se inclinou ao enquadramento na classe média, e a escolha de um dos três estratos (alta, média, baixa) permitiu diferenciá-los.

7 Após a leitura do dendograma, a análise de cluster foi realizada com o número pré-definido de 5 agrupamentos pelo método $k$-means, entendendo que a organização do espaço profissional segue muito mais uma lógica iterativa do que hierárquica.

\section{BIBLIOGRAFIA}

ABBOTT, Andrew (1988), The system of professions: an essay on the division of expert labor. Chicago/ London, The University of Chicago Press.

ARTES, Amélia; RICOLDI, Arlene Martinez (2015), "Acesso de negros no ensino superior: o que mudou entre 2000 e 2010". Cadernos de Pesquisa, 45, 158: 858-881.

BARBOSA, Maria Ligia de Oliveira (1993), Reconstruindo as Minas e planejando as Gerais: os engenheiros e a constituição dos grupos sociais. 
Tese de doutorado, Instituto de Filosofia, Letras e Ciências Humanas, UNICAMP, Campinas.

BARBOSA, Maria Ligia de Oliveira (2014), "O ensino superior no Brasil: credencial, mérito e os coronéis", in M. L. O. Barbosa (org.), Ensino superior: expansão e democratização, Rio de Janeiro, 7 Letras.

BARBOSA, Maria Ligia de Oliveira (2015), "Destinos, escolhas e a democratização do ensino superior". Politica e Sociedade, 14, 31: 256-282.

BARBOSA, Maria Ligia de Oliveira; SANTOS, Clarissa Tagliari (2011), "A permeabilidade social das carreiras do ensino superior". Caderno $C R H$, 24, 63: 535-554.

BERTONCELO, Edison (2016), "O espaço das classes sociais no Brasil”. Tempo Social, 28, 2: 73-104.

BERTONCELO, Edison (2019), "Classe social e alimentação: padrōes de consumo alimentar no Brasil contemporâneo". Revista Brasileira de Ciências Sociais, 34, 100: e3410005.

BOURDIEU, Pierre (2007), A distinção: crítica social do julgamento. São Paulo/Porto Alegre, Edusp/Zouk.

BRASIL. Presidência da República, Casa Civil. (1986), Lei no 7.498, de 25 de junho de 1986. Dispóe sobre a regulamentação do exercício da enfermagem, e dá outras providências. Disponível em http://www.planalto.gov.br/ccivil_03/leis/ 17498.htm, consultado em 9/4/2018.

BRASIL. Presidência da República, Casa Civil. (2013), Lei no 12.842 , de 10 de julho de 2013. Dispóe sobre o exercício da medicina. Disponível em http://www.planalto.gov.br/ccivil_03/_ato20112014/2013/lei/112842.htm, consultado em $9 / 4 / 2018$.

BRINT, Steven (1992), "Profesiones y mercado". Revista Española de Investigaciones Sociológicas, 59: 161-203.

BRITO, Murilo Marschner Alves (2017), "Novas tendências ou velhas persistências? Modernização e expansão educacional no Brasil". Cadernos de Pesquisa, 47, 163: 224-263.

CFM - Conselho Federal de Medicina. (2016), Resolução CFM no 2.149/2016. Homologa a Portaria CME no 02/2016, que aprova a relação de especialidades e áreas de atuação médicas aprovadas pela Comissão Mista de Especialidades. Disponível em http://www.portalmedico.org.br/ resolucoes/cfm/2016/2149_2016.pdf, consultado em $9 / 4 / 2018$.

CHAVES, Miguel; MORAIS, César (2014), "Nivelação e desigualdade na inserção profissional de diplomados do ensino superior". Sociologia, problemas e práticas, 76: 87-108.

CHAVES, Miguel; NUNES, João Sedas (2011), "As classes sociais já não contam? Advocacia e reprodução social”. Sociologia, problemas e práticas, 66: 49-70.

COLLINS, Randall (2013), "The end of middle-class work: no more escapes", in I. Wallerstein et al., Does capitalism have a future? New York, Oxford University Press.

CORADINI, Odaci Luiz (2010), "Titulação escolar, condição de 'elite' e posição social". Revista Brasileira de Educação, 15, 43: 45-69.

CORADINI, Odaci Luiz (2014), "Efeitos da educação formal, categorias ocupacionais e posição social". Revista Sociedade e Estado, 29, 2: 511-538.

CORADINI, Odaci Luiz (2015), "Mercado escolar, de trabalho e usos da titulação universitária". Revista Pós Ciências Sociais, 12, 23: 115-132.

DINIZ, Marli (1996), "Neomarxistas e neoweberianos: sobre a natureza do estrato profissional”. Dados - Revista de Ciências Sociais, 39, 1: 101-137.

DINIZ, Marli (2001), Os donos do saber: profissóes e monopólios profissionais. Rio de Janeiro, Revan.

DUBET, François; DURU-BELLAT, Marie; VÉRÉTOUT, Antoine (2012), "As desigualdades escolares antes e depois da escola: organização escolar e influência dos diplomas". Sociologias, 29: 22-70.

FREIDSON, Eliot (1986), Professional powers: a study of the institutionalization of formal knowledge. Chicago, The University Chicago Press.

FREIDSON, Eliot (2008), Profissão médica: um estudo de sociologia do conhecimento aplicado. São Paulo/Porto Alegre, Editora Unesp/Sindicato dos Médicos.

GIRARDI, Sabado Nicolau et al. (2014), Estudo de levantamento de aspectos demográficos, de formação 
e de mercado de trabalho das profissóes de saúde de nivel superior no Brasil entre 1991 e 2010. Relatório de Pesquisa. Belo Horizonte, EPSM/ Nescon/FM/UFMG. Disponível em http:// epsm.nescon.medicina.ufmg.br, consultado em 21/2/2015.

GRUSKY, David; SORENSEN, Jesper (1998), "Can class analysis be salvaged?". American Journal of Sociology, 103, 5: 1187-1234.

GUEDES, Moema Castro (2010), "A inserção dos trabalhadores mais escolarizados no mercado de trabalho brasileiro: uma análise de gênero". Trabalho, Educação e Saúde, 8, 1: 55-75.

KLÜGER, Elisa (2018), "Análise de correspondências múltiplas: fundamentos, elaboração e interpretaçáo". BIB - Revista Brasileira de Informaçāo Bibliográfica em Ciencias Sociais, 86: 68-97.

LARSON, Magali Sarfatti. (2013), The rise of professionalism: monopolies of competence and sheltered markets. New Brunswick/London, Transaction.

MAAS, Lucas Wan Der (2018), “Análise comparativa da base social da medicina e enfermagem no Brasil entre os anos de 2000 e 2010". Cadernos de Saúde Pública, 34, 3: e00199116.

MADALOZZO, Regina; ARTES, Rinaldo (2015), "Escolhas profissionais e impactos no diferencial salarial entre homens e mulheres". Cadernos de Pesquisa, 47, 163: 858-881.

MINGOTI, Sueli Aparecida (2005), Análise de dados através de métodos de estatistica multivariada: uma abordagem aplicada. Belo Horizonte, Editora UFMG.

MONTAGNER, Miguel Ângelo. (2007), "Trajetórias e biografias: notas para uma análise bourdieusiana". Sociologias, 9, 17: 240-264.

MONT’ALVÃO, Arnaldo (2011), "Estratificação educacional no Brasil do século XXI". Dados Revista de Ciências Sociais, 54, 2: 389-430.

MONT'ALVÃO, Arnaldo (2015), "Diferenciação institucional e desigualdades no ensino superior".
Revista Brasileira de Ciências Sociais, 30, 88: 87-143.

PRATES, Antônio Augusto Pereira; COLLARES, Ana Cristina Murta (2014), Desigualdade e expansão do ensino superior na sociedade contemporânea: 0 caso brasileiro do final do século $X X$ ao princípio do século XXI. Belo Horizonte, Fino Traço.

REIS, Maurício; MACHADO, Danielle (2015), Uma análise dos rendimentos do trabalho entre individuos com ensino superior no Brasil. Textos para Discussão, no 2110. Brasília, Ipea.

RIBEIRO, Carlos Antônio Costa (2011) "Mobilidade e estrutura de classes no Brasil contemporâneo". Sociologias, 16, 37: 178-217.

RIBEIRO, Carlos Antônio Costa (2016), "Desigualdades de gênero no ensino superior e no mercado de trabalho no Brasil: uma análise de idade, período e coorte". Revista Sociedade e Estado, 31, 2: 301-323.

RIBEIRO, Carlos Antônio Costa; SCHLEGEL, Rogerio (2015), "Estratificaçáo horizontal da educaçáo superior no Brasil (1960 a 2010)", in M. Arretche (org.), Trajetórias das desigualdades: como o Brasil mudou nos últimos cinquenta anos, São Paulo, Editora Unesp/CEM.

SALATA, André (2014), Quem é a classe média no Brasil? Um estudo sobre identidades de classe. Tese de doutorado, Programa de Pós-Graduaçáo em Sociologia e Antropologia, UFRJ, Rio de Janeiro.

SANTOS, José Alcides Figueiredo (2014), "Classe média e mudanças de renda no Brasil". Revista Brasileira de Sociologia, 2, 4: 83-107.

SANTOS, José Alcides Figueiredo (2015), "Mudanças de renda no Brasil: fatores espaciais, setoriais, educacionais e de status social". Sociedade e Estado, 30, 3: 749-772.

WEEDEN, Kim (2002), "Why do some occupations pay more than others? Social closure and earnings inequality in the United States". The American Journal of Sociology, 108, 1: 55-101. 


\section{PROFISSÁO E ESTRATIFICAÇÁO SOCIAL: DESIGUALDADES NAS TRAJETÓRIAS DE MÉDICOS E ENFERMEIROS NO BRASIL ATUAL}

\author{
Lucas Wan Der Maas, Alessandra \\ Sampaio Chacham, Maria Carolina \\ Tomás
}

Palavras-chave: Profissão; Desigualdades; Estratificação social; Medicina; Enfermagem.

$\mathrm{O}$ artigo tem por objetivo analisar as desigualdades nas trajetórias profissionais de médicos e enfermeiros no Brasil atual, a partir de uma abordagem quantitativa que permitiu contrastar trajetórias representativas de diferentes posiçóes no espaço profissional. Os dados derivam de um survey on-line aplicado em uma amostra composta por 188 médicos e 186 enfermeiros. Parte-se do pressuposto de que as trajetórias tendem a se diferenciar de acordo com recursos herdados da família de origem, o percurso de formação no ensino superior (graduação e pós-graduação), o tipo de inserção no mercado de trabalho e o estágio na carreira. A abordagem metodológica utilizou a combinaçáo de Análise de Correspondências Múltiplas e análise de cluster. Os resultados contribuem para o entendimento de como as diferenças inter e intraprofissóes tanto reproduzem quanto reforçam as desigualdades no interior do espaço profissional.

\section{PROFESSION AND SOCIAL STRATIFICATION: INEQUALITIES IN THE TRAJECTORIES OF PHYSICIANS AND NURSES IN TODAY'S BRAZIL}

Lucas Wan Der Maas, Alessandra Sampaio Chacham and Maria Carolina Tomás

Keywords: Profession; Inequalities; Social stratification; Medicine; Nursing.

The article aims to analyze the inequalities in the professional trajectories of doctors and nurses in today's Brazil, from a quantitative approach that allowed for the contrast of representative trajectories concerning different positions in the professional space. The data are derived from an online survey applied to a sample of 188 doctors and 186 nurses. It is assumed that trajectories tend to differ according to resources inherited from the family of origin, higher education training course (undergraduate and graduate), type of insertion in the labor market and career internship. The methodological approach applied the combination of a Multiple Correspondence Analysis and cluster analysis. The results contribute to the understanding of how inter- and intra-professional differences both reproduce and reinforce inequalities within the professional space.

\section{PROFESSION ET STRATIFICATION SOCIALE: INÉGALITÉS DES TRAJECTOIRES DES MÉDECINS ET INFIRMIERS DANS LE BRÉSIL ACTUEL}

\author{
Lucas Wan Der Maas, Alessandra \\ Sampaio Chacham et Maria Carolina \\ Tomás
}

Mots-clés: profession ; inégalités ; stratification sociale; médecin ; infirmier.

Pour analyser les inégalités existantes au niveau des trajectoires professionnelles de médecins et d'infirmiers dans le Brésil d'aujourd'hui, ce travail s'est valu d'une approche quantitative capable de comparer des parcours représentatifs de différentes positions dans le milieu du travail. Les données ont été obtenues à partir d'une enquête en ligne auprès d'un échantillon composé de 188 médecins et 166 infirmiers. L'étude part du présupposé que les trajectoires tendent à être différentes en fonction des ressources de la famille d'origine, du parcours de formation dans l'enseignement supérieur (licence et master), du type d'insertion sur le marché du travail et du stage professionnel. L'approche méthodologique associe l'analyse des correspondances multiples et l'analyse de cluster. Les résultats indiquent que les différences intra- et interprofessions reproduisent et même renforcent les inégalités à l'intérieur de l'espace professionnel. 